\title{
Presentation of brucellosis in an endemic area; west of IRAQ
}

\author{
Haitham N. Al- Koubaisy ${ }^{1}$ and Shehab A. Lafi ${ }^{2}$
}

1- Department of Medicine, College of Medicine, Al-Anbar University West of IRAQ.

2- Microbiology Department, College of Medicine, Al-Anbar University West of IRAQ. E mail Shehab 58@yahoo.com

\begin{abstract}
Background: brucellosis in enzootic bacterial infection of animals and human through infected animals milk, urine, vaginal secretions, uterine products \& uncooked infected meat. leads to clinical human infection with brucellosis.

Objectives: this study was introduced to look for endemicity, presentation\& rate of infection of brucellosis in Anbar Governorate West of Iraq.

Materials \& methods: one hundred four (104) patients had clinical features of brucellosis investigated serologically, blood cultures. received antibrucella of triple antibiotics for minimum 6 weeks followed up regularly till they cured, during the period from 30.12.2009 to 30.12.2010.

Results: one hundred four (104) cases were diagnosed, fifty four of them (54) were females and fifty (50) were males all of them were adults .Ninety six (96) cases were presented with subacute brucellosis, three (3) cases with knee joint arthritis, (four) 4 cases with sciatic nerve radiculopathy and one case of neurobrucellosis.

Conclusion: the study proved that Anbar Governorate is endemic with brucella infection with mild symptoms in most cases and good response with no relapse rate with triple antibrucella antibiotics.
\end{abstract}

Keywords: Brucellosis, Zoonosis, Endemicity

\section{INTRODUCTION}

Brucella is Gram negative bacteria (bacilli) it is intracellular bacteria especially in the reticuloendothelial system so it has the ability for chronicity and relapse $(1,2,3)$.it is enzootic, infect animals (cattle, sheep, goats, equines, swine \&camels). It is secreted through the animals milk, uterine secretions, vaginal secretion, urine \& faeces other animals can get infection through consumption of these products or infected meat e.g. dogs which will be other source to infect human and increase endemicity of brucellae in the area. human infected by consuming infected unpasteurized milk, cheese ,yogurt \& butter or consuming uncooked meat. human get infection also through wounds or skin abrasions as contaminated e.g. in animal laboring not wearing gloves or carrying infected animal placenta by human hands and the bacteria enter to human through the wounds or abrasions $(1,2,3,4)$.

A serological surveillance was done and revealed the prevalence of the disease in sheep, goats, cattle, buffalo and camels was $6.51 \%, 1 \%, 1.84 \%$ and $0.02 \%$ respectively in IRAQ Except Kurdistan governorate. In spite of the lack of appropriate recording in the middle and south of Iraq, the incidence rate of brucellosis in human after the 2003 war was 5347 recorded cases representing 22.7 cases/100,000 people, (5).

There are six species of brucellae, four of them are important for human. Br. melitensis (infects sheep, goats \& camels), Br. abortus (infects cattle), Br. canis (infects dogs), Br. suis (infects swine) (2) . 
Brucellosis in human can be presented as an acute infection, subacute or chronic infection. It may be presented as localized organ infection. In Acute presentation, the patient complaining of intermittent fever, profuse sweating, headache, arthalagia, rigor, spleenomegaly which may lead to hyperspleenism and any localized organ involvement if the diagnosis \& treatment delayed which may infect musculoskeletal system central nervous system, ocular, cardiac, respiratory, abdominal, genitourinary systems \& hematological system $(1,3)$.

Brucella diagnosis is definitely by isolation of bacteria by blood culture, but isolation method carry risk of infection to the laboratory workers $(\mathrm{Br}$. mellitensis $75-80 \%$. Br. abortus 50\%) $(6,7)$.

Rose- Bengal test, which is serological test by slide method (antigen antibody test) is positive in infected patients in $95 \%$ of acute infection it needs several weeks to become positive $\&$ remains positive after cure of the patient for many years. It has the character of prozone phenomenon which is false negative result of Rose Bengal test due to concentrated serum, with dilution of test serum the result becomes positive. In endemic area the titer of $1 \backslash 320$ or four rise in the fold of titer is considered positive. In high endemic area. Rose- Bengal test is considered screening test.

Prove of the previous or new infection is by 2-mercaptoethanol test, positive indicate recent infection $(6,7)$. Tube agglutination test is more diagnostic yield for brucellosis (7). In localized infection e.g. brucella arthritis in addition to above investigations, radiological study like $\mathrm{X}$ - ray study, aspiration of synovial fluid with bacteriological culture.

Neurobrucellosis is diagnosed in addition to above investigations by MRI of the brain \& CSF study for RoseBengal study \& CSF culture $(1,3,8)$.
Brucella is treated by doxycycline capsules $100 \mathrm{mg} 12$ hourly for 6 weeks.

Rifampicine capsules $600 \mathrm{mg}-900$ $\mathrm{mg}$ for 6 weeks .Streptomycin vial for first two weeks $750 \mathrm{mg}$ for patient less than $50 \mathrm{~kg} \backslash \mathrm{BWT}$ and $1 \mathrm{gm}$ for patients more than $50 \mathrm{~kg} \backslash \mathrm{BWT}$, multidrug regimen carry good response result and low relapse rate e.g. doxycycline+rifampicine has relapse rate of $5 \%$, doxycycline+streptomycin is another regimen $(1,3,9,10)$.

\section{MATERIALS AND METHODS}

The study done over one year from 30-12-2009 to 30-12-2010, one hundred (104) adult patients were presented with brucellosis.

Full history was taken, well clinically examined, investigated laboratory by Rose-Bengal test with dilution method, 2ME test, tube agglutination test following (Hudson and Hay 2000) 11 .

Blood culture was done on Castaneda medium by inoculation of $3 \mathrm{ml}$ of patient blood following guidelines of (Vadepitte et al. 2003.)13. Bacterial isolates were identified by direct Gram stain and biochemical tests following (Washington 2005)6 Patients received triple therapy antibiotics of doxycycline $100 \mathrm{mg}$ twice daily, rifampicine $600 \mathrm{mg}$ daily for six weeks \& early use of streptomycin vial for 2 weeks there was good response for this regimen. Patients followed up for 6 weeks till complete cure $\&$ followed up regularly for relapse which was negative for all my patients. Six (6) months treatment for the patient with neurobrucellosis with good outcome was documented clinically with MRI study follow up with blood culture and serological study.

\section{RESULTS}

One hundred four (104) cases of adult patients of brucellosis over one year had been diagnosed all of them from different towns of Anbar Governorate, fifty four (54) of them were females and 
fifty (50) were males. Most of the cases $95 \%$ were from rural areas and most of these patients rear animals cattle, sheep $\&$ goats beside their houses in their farms, the patients were advised to examine their animals by veterinarian doctors and $90 \%$ of them gave history of their animals infection with brucella.
Five $(5 \%)$ of patients were from urban areas. Most of the cases were young patients between the age of $20-30$ years (39 cases) \& lowest rate of infection was between 61-70 years (9 cases) (Table 1, Table 2).

Table1: Age groups and patient number

\begin{tabular}{|c|cc|}
\hline Age & \multicolumn{2}{|c|}{ Number of patients } \\
\hline $20-30$ & 39 & $37.5 \%$ \\
\hline $31-40$ & 17 & $16.4 \%$ \\
\hline $41-50$ & 20 & $19.23 \%$ \\
\hline $51-60$ & 19 & $18.3 \%$ \\
\hline $61-70$ & 9 & $8.6 \%$ \\
\hline Total & 104 & $100 \%$ \\
\hline
\end{tabular}

Table 2 sex related to number of patients.

\begin{tabular}{|c|cc|}
\hline Sex & Number of patients \\
\hline Male & 50 & $48.0 \%$ \\
\hline female & 54 & $52 \%$ \\
\hline
\end{tabular}

There was seasonal variation in the season (during the period from March to incidence of brucellosis over the year, May) \& lowest cases within winter most of the cases are within spring (From October to February) (Fig.1).

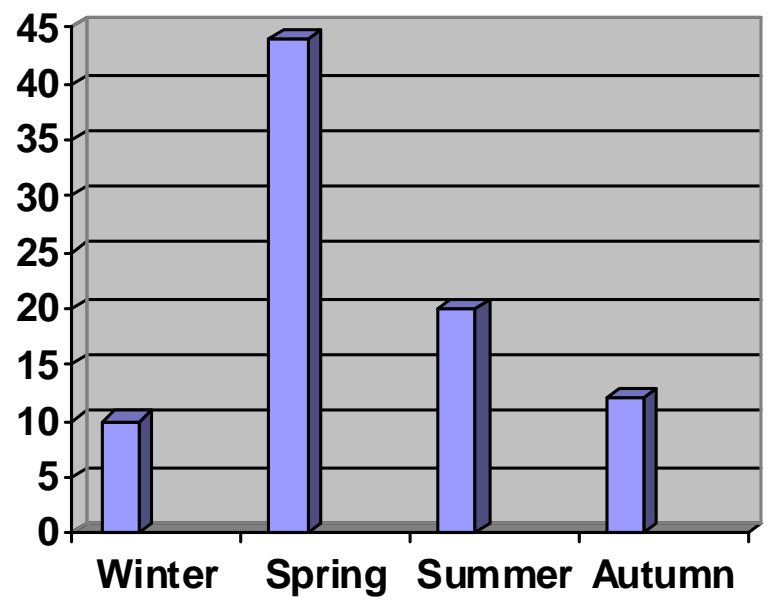

Fig. 1: Seasonal variation of Brucellosis

\section{DISCUSSION}

The patients whom diagnosed with brucellosis were adults this was ought to the sampling method, we are dealing with adults patients in our private clinic and other sites from where cases were collected. The number of patients was 104 patients most of them from rural areas when advised to examine their animals for Brucellosis to prove animal infection. Previous studies in Al-Anbar governorate in 1994 and 2006 (AlAzawi and Lafi 1994 13 , Al-Ouqayli $2006_{14}$ ) as well as the study of Salih $2010_{5}$ ) on the epidemiology of brucellosis in IRAQ, all the studies 
proved that humans were infected with brucellosis so that the area of study (West of Iraq) is still endemic with human zoonotic brucellosis and this was due to unapplied system of test and slaughter for animal infection eradication as in Europe and other advanced countries . Infected animals must be eradicated by slaughtering and burning of the infected animals because there is no curable medical therapy for brucellosis in animals (Source of human infections), the animals in this area (west of Iraq) are expensive so the farmers refused strongly to slaughter their infected animals and burning them so the infection persist and transmit infection to their children by breast feeding and other animals whom consume their infected milk on other hand this infected milk if consumed unpasteurized by human it leads to human infection so the area will be endemic with brucellosis both to animals and human . non significant difference was found between males and females while in other countries which are endemic with brucellosis $(9,15,16,17)$.

So as in Egypt(18),Sudan(19) and Ethiopia (20) the females were more in number than males whom get infection and most of the infected patients were young to middle age, because both sexes are working in the farm and take care of their animals. Females looks after animals more than males so they get infection relatively more than males.

Our explanation for age and sex variation in the rate of infection in the area of the study was ought to the fact that in Iraq all family individuals are working in the farm and care of the animals young and middle age e.g. laboring animals by themselves without protecting themselves, not examining animals for Brucella infection, milking animals, drinking raw infected milk immediately, leads to infection with Brucella old age less contact with animals they get infection through consuming unpasteurized milk and its production. We found $5 \%$ of cases were among urban patients while (Yacoub et al. 2006 21) were found that the prevalence of brucellosis was higher in the suburban semirural area $(29.3 \%)$ than the rural and urban areas of Basra region and this was dis agree with that reported by (Al Azawi and Lafi 199413) in AlAnbar govoernorate.

Seasonal variation was found for presentation of brucellosis, higher rate of infection was found in spring, this was in accordance with (Al-AzawI and Lafi $1994_{13}$ Salih 2010 ). This was ought to the animal reproduction increase and milk production increase in this season in Anbar Governorate and other sites of IRAQ in addition to that the organism can sustain environmental conditions (temperature, $\mathrm{PH}$, moisture etc.) in this season more than other seasons of the year (Eurepian Comission 2001 22). The presentation of most of the cases was mild due to high endimicity and exposure of brucellosis so increase the body immunity 1,2). The most of bacteria which isolated were Brucella abortus which is usually has mild presentation of symptoms $(2,6)$.

There was only one case of neurobrucellosis it is very rare world wide (7) and this is the first case registered in this area the case was female from urban area, lately diagnosed and treated.

The cases presented with oligoathritis (both knee joints ) diagnosed by synovial fluid aspiration with bacteriological culture which prove B.abortus which is common bacteria in Anbar Governorate .Brucella bacteria has the tendency to involve the locomotor system especially the large joints.

Neuritis \& neuropathy are another common presentation of acute, subacute \& chronic brucellosis as with my study three cases of sciatic radiculopathy was presented which show low percent of localized organ involvement due to good immunity of patients and low virulence 
of bacteria and good awareness of patients to symptoms looking care for themselves for treatment earlier.

Spleenomegaly occur as part of reticuloendothelial system involvement it occurs in $30 \%$ in brucellosis cases (1) but in this study the percent of presentation of spleenomegaly is much less $(1.04 \%)$ due to endemicity and high exposure rate which affect immunity of the patients and affect presentation of the cases and due to bacteriological factors and patients factors due to early diagnosis and treatment of the patients where they look for medical advice early in the disease.

The cases respond very good to triple antibrucella antibiotics early 2 weeks of streptomycin vial with doxycycline capsules $100 \mathrm{mg}$ twice daily \& refampicine capsules 600mg-900mg daily for 6 weeks all cases cured no relapse of brucellosis in follow up of the cases with negligible side effects .this in comparison with study of dual therapy treatment of brucellosis (streptomycin or gentamycine plus doxycycline capsules) showed good response clinically but with relapse rate of $5-10 \%(8)$. So that triple therapy is curative no relapse rate due to good penetration to infected organs and eradication of bacteria and this was in agreement with the findings of (Al-Ani 1990) 23 .

We can conclude from this study that Anbar Governorate is considered as one of the endemic areas with brucellosis this needs surveillance and follow up through brucella center for diagnosis, treatment, prevention \& education. AS well as activation of veterinary branch as well as activation and follow up of vaccination campaign through program supervised by FAO and SCVS (OSR0/IRQ/406/UDG,) Restoration and Development of Veterinary Services in Iraq.

\section{REFERRENCES}

1- Nicki, R.; Colledge, Brian R.; Walker Stuart H. Ralston (2010). Davidson textbook of medicine 21 st edition . page 329.

2- Brooks E. G.; Carroll C.K., Butel. S. J. (2007): the Brucell in jawetz, Melnick and Adelberg $\mathrm{s}$ medical microbiology $24^{\text {th }}$ edition .page 285 287 .Macgraw Hill Publi newYork USA.

3- Fauci S.A., Braunwald B., Kasper L.D. et al. (2008): brucellosis in Harrison $\mathrm{s}$ principles of internal medicine $\left(7^{\text {th }}\right.$ ed. P. 973 vol.1) Mc Graw Hill publisher new York USA.

4- Abbas, B. A. and A. B. Aldeewen. 2009. Occurrence and epidemiology of Brucella spp. in raw milk samples at Basrah province, Iraq. Bulgarian $\mathrm{J}$. Vet. Med. 12: 136-142.

5- Salih H. M. S. (2010). Brucellosis in Iraq : Epidemiology, Present status and Challenge in Controlling the Disease. A thesis Submitted in partial fulfillment of the requirements for the degree MASTER OF SCIENCE Department of DiagnosticMedicine/Pathobiology College of Veterinary Medicine KANSAS STATE UNIVERSITY , Manhattan, Kansas 2010.

6- Washington, W. Jr.; Allen, S. and Janda, W. et al. (2006). Koneman s color atlas and textbook of diagnostic microbiology $6^{\text {th }} \quad P \quad 482-490$. Lippincott Williams \& wilkins published UK. London.

7- Wafa Al-nassir, Michelle V. and Robert A. (2009): "Brucellosis" eMedicine infectious disease. internet: emedicine.medscape.com/article/213 430-overview.

8- Al-Sous M. W.; Bohlega S.; Al-Kawi, M. Z.; Alwatban, J. and Mclean D .R. (march 2004). "Neurobrucellosis: Clinical and neuroimaging correlation". AJNR Am. J. $\begin{array}{lll}\text { Neuroradiology } 25 & \text { (3):395-401. }\end{array}$ Iternet:

www.ajnr.org \cgi \pmidlookup?view=longH YPERLINK

"http://www.ajnr.org/cgi/pmidlookup?view=1 ong\&pmid=15037461"\&HYPERLINK

"http://www.ajnr.org/cgi/pmidlookup?view=1 ong\&pmid=15037461"pmid=15037461. 
9- M. Ghaffarpour; A.Khoshroo, M. H.; Harirchian, et al. (2007). Clinical, epidemiological,labrotory and imaging aspects of brucellosis with and without neurological involvement .acta medica iranica. 45(1): 63-68.

10- Hasanjani, R.; Mohraz, M. and Hajiahmadi, M. (2006): "Efficacy of gentamycin plus doxycycline versus streptomycin plus doxycycline in the treatment of brucellosis in humans ". Clinical Infectious Disease 42 (8):1075-80.

11- Hudson L. and Hay F.C. (1989). Practical immunology, Third ed. P. 230 Blackwell Scientific Publications London UK.

12- Vandepitte, J.; Verhaegen, J. and Engbaek, K. (2003). Basic laboratory procedures in clinical bacteriology Second ed., WHO, Geneva, Switzerland.

13- Al-Azawi, H. S. and Shehab, A. Lafi (1994). A study on Brucellosis In AlAnbar Governorate. J. Fac. Med. Baghdad, Vol. 36, NO. 1.

14- Al-Ouqaili, M. T. S. (2006). Molecular, bacteriological and immunological aspect in the diagnosis of human brucellosis, a thesis of Doctorate degree in Microbiology Department, College of Medicine ,Baghdad University.

15- Ts. Dimitrove; D. Panigrahi and M. Emara, (2004). "Seroepidemiological and Microbiological study of brucellosis in Kuwait "Medical principles and practice 13 (4): 215 219.

16- QM.Abushaqra (2000). Epidemiological aspects of brucellosis in Jordan .Eur. J.epidemiology 16 (6):581-594.

17- Youssef A. AL-Eissa (1999). Brucellosis in Saudia Arabia: past, present and future . Annals of Saudi Medicine , 19(5): 403-405.

18- Hassan S.; Al-Rowaily, M. and Ramadan, M. (2008). Multicenter study of brucellosis in Egypt . Emerging Infectious Disease 14 No. 12 .page 1916-1918.

19- El-Hassan H. and El-Ansary, Babiker A., (2001). Brucellosis among animals and human contacts in eastern Sudan .saudi medical j. 22 (7):577-579.

20-Gene Regassa, Desalew, M. and Lawrence, y. (2009). Human brucellosis in traditional pastoral communities in Ethiopia .international journal of Internal Medicine, 4:59-64.

21-Yacoub, A. A-H.; S. Bakr; A. M. Hameed; A. A.; Al-Thamery, and M. J. Fartoci. (2006). Seroepidemiology of selected zoonotic infections in Basra region of Iraq. La Revue de Sante de la Mediterranean orientale. 12: 112-118.

22-European Commission. 2001. Scientific committee on animal health and animal welfare. Brucellosis in Sheep and Goats (Brucella melitensis).

23-Al-Ani M.M. (1990). Treatment of Brucellosis with Doxycycline and Refampicine Iraq Med. J. 39: 9-12

\section{ARABIC SUMMARY}

\section{عرض لجرثومة حمى مالطة فى الاماكن المتوطنة بغرب العراق.}

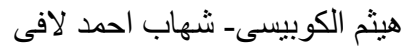

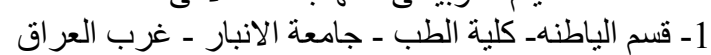

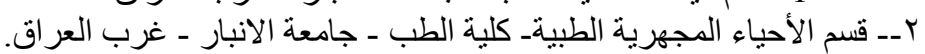

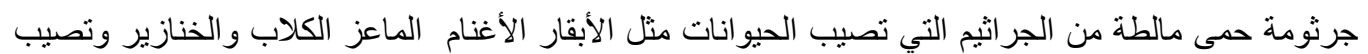

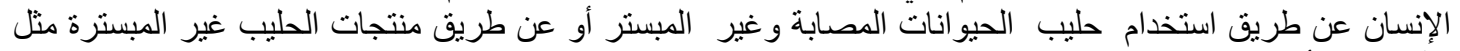

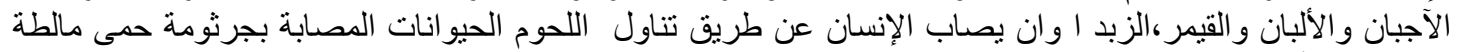

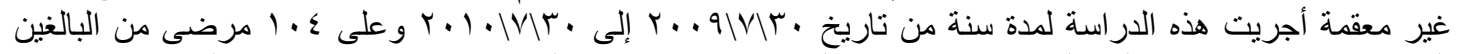

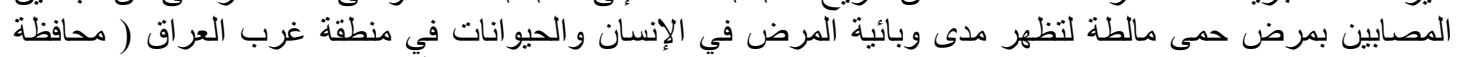

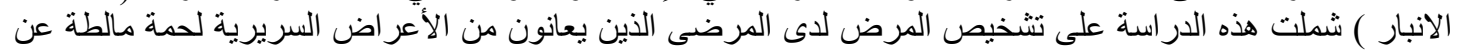

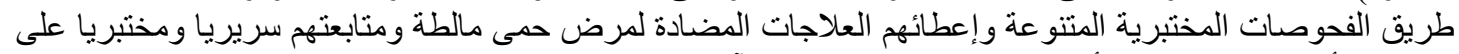

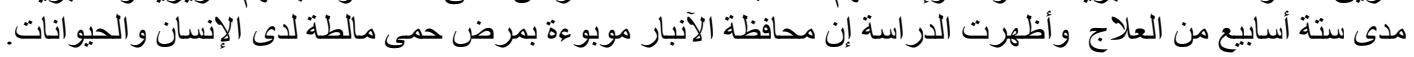

